\title{
Genetic Counseling and the Central Tenets of Practice
}

\author{
Barbara Biesecker \\ RTI International, Washington, D.C. 20005, USA \\ Correspondence: bbiesecker@rti.org
}

Genetic counseling is a profession growing and evolving at an extraordinary rate. This growth is driven by an explosion in what we know, as a result of progress in science, technology, and bioinformatics, and an explosion in what we do not know, as we strive to understand the impact of genomic information on the lives of our patients and clients. Genetic counselors work in an increasing number of subspecialties and diversity of settings. But although the field has evolved, it has maintained a remarkably unchanged core of shared values and beliefs. The heart of genetic counseling practice is the therapeutic relationship, with its dual role of providing information and facilitating assimilation of that information to personalize healthrelated decision-making and foster successful adaptation. Genetic counseling aims to communicate cutting-edge genomic science within an empathic understanding of the client/ patient's concerns and needs. In pursuit of these goals, further assessment of genetic counseling's effectiveness is needed to facilitate evidence-based practices and to scale counseling resources.

G enetic counseling is a rapidly evolving proIfessional practice that has kept pace with emerging genetic technologies and related patient/client ${ }^{1}$ needs. Translational genomics and personalized medicine are beginning to make their mark, and genetic counseling in various subspecialties has expanded accordingly. Regardless of the changes, what remains unwavering and central to the identity of the profession is the therapeutic relationship between the counselor and the patient/client. This approach originated with recognition of the sensitivities around genetic illness and risks and the resultant difficult decisions and uncertainties. Built upon the centrality of these concerns, a typical session would involve the counselor assessing the patient/client's genetics-related needs, exchanging and discussing relevant information, and eliciting the patient/client's relevant thoughts and feelings to advance the relationship to one of empathic understanding. Within this relationship, the patient/client can be helped to reach a goal, such as making an informed decision, assimilating effective coping strategies to facilitate adaptation to living with at an increased risk, gaining relevant personal insight into living

\footnotetext{
1"Patient/client" is used throughout as genetic counseling is provided to those who are ill and those who are healthy and may not even be at increased risk.

Editors: Laura Hercher, Barbara Biesecker, and Jehannine C. Austin

Additional Perspectives on Genetic Counseling: Clinical Practice and Ethical Considerations available at

www.perspectivesinmedicine.org

Copyright (C) 2020 Cold Spring Harbor Laboratory Press; all rights reserved; doi: 10.1101/cshperspect.a038968

Cite this article as Cold Spring Harb Perspect Med 2020;10:a038968
} 
with a condition, or empowerment to enhance one's quality of life.

One way in which genetic counseling remains stubbornly difficult to define is the range of genetics-related needs that patients/clients bring to counseling, and the specialization of services provided. Reasons for counseling may vary from an elevated risk for an untreatable neurodevelopmental disorder to the routine discussion of a prenatal screening test. Although genetic testing may be on offer, genetic counseling is not exclusively linked to testing. Take, for example, the case of parents of a son with an undiagnosed complex developmental disability who was previously tested; these parents may seek genetic counseling to learn about his prognosis. The counselor would facilitate a discussion about their need for new information and contact with parents of similarly affected children. S/he would help them work through a variety of challenges, including tensions in their marriage related to the stress of coping with their son's disability and barriers to addressing their relatives' concerns about their risks for having a similarly affected child. Whereas communicating and clarifying an understanding of genetic information are common elements in genetic counseling, psychotherapeutic counseling to address resultant responses to the stress of living at risk of or with a genetic condition is, at times, even more pertinent to the job of addressing patient/client needs (Austin et al. 2014; Biesecker et al. 2017).

\section{DELINEATING PRACTICE}

Because of the variety of settings and patient/ client needs and a limited evidence base, genetic counseling was previously described as a black box (Biesecker and Peters 2001). However, the National Society of Genetic Counselors (Resta et al. 2006) has successfully defined genetic counseling as the "process of helping people understand and adapt to the medical, psychological and familial implications of genetic contributions to disease. This process integrates: Interpretation of family and medical histories to assess the chance of disease occurrence or recurrence; education about inheritance, testing, manage- ment, prevention, resources and research; and counseling to promote informed choices and adaptation to the risk or condition." This definition has been cited often and taught in most, if not all graduate programs across the globe (Resta et al. 2018). In 2007, a novel practice model for clientcentered care, the reciprocal engagement model (REM), was developed by directors of North American graduate programs in genetic counseling (Veach et al. 2007). The REM has at its center the relationship between the counselor and patient. The tenets of practice proposed for the REM include:

1. Genetic information is key.

2. The relationship is integral.

3. Patient autonomy must be supported.

4. Patients are resilient.

5. Patient emotions make a difference.

To develop a fuller, more nuanced understanding of the tenets, I have extended them:

1. Information is key and must be accurate in reflecting cutting-edge genomic science.

2. The relationship is integral and should be psychotherapeutic.

3. Patient autonomy is important, but at times may be challenged in the interest of mitigating health risks.

4. Patients are resilient and capable, but some are vulnerable and need further interventions.

5. Patients' affect reflects only one of a triad of psychological responses to genetic information-cognition, affect, and behaviorall of which are important patient/client experiences to be addressed in genetic counseling.

These five tenets remain true to the field despite the ways it has adapted to technological advances in genomics. From its early days, when diagnoses and etiology of disease were hard to come by, genetic counseling came to include a diverse range of practices and specialty settings. Today, the diagnosis of genetic conditions oc- 
curs regularly, and risk information is more precise because of advances in genetic/genomic testing. As such, the roles and responsibilities of genetic counselors have advanced to include making medical recommendations (Matias et al. 2019; Subas et al. 2019; Zakas et al. 2019), working to modify health behaviors (Rutherford et al. 2014; Milliron et al. 2019), and facilitating communication and testing among at-risk relatives (Montgomery et al. 2013), while engaging in psychotherapeutic counseling (Austin et al. 2014; Biesecker et al. 2017). With the growth in genetic counseling have come expanded responsibilities and opportunities for creative use of familiar skills. Many of these broadening responsibilities continue to reflect client-centered care and the tenets of genetic counseling practice (Resta et al. 2006; Veach et al. 2007). Yet because of diversification and novel interactions with patients/clients, genetic counseling now also extends beyond patient/client-centered care. Aspects of what has historically been considered genetic counseling practice can be delivered by nongenetic counselor resources using, for example, artificial intelligence and digital platforms. These challenges to the REM and its original tenets are based on the need to be relevant across subspecialty settings and to meet growing patient/client needs, requiring genetic counseling to embrace alternative service delivery models and recognize resources to augment and even replace components of genetic counseling when patient/client needs can still be met (see Cho and Guy 2019; Ramos 2019). For example, many genetic counselors work in the laboratory setting; in 2018, 22\% worked for companies that provide genetic testing (https ://www.nsgc.org/p/cm/ld/fid=68), complicating their practice with parallel roles as clinical experts and business representatives. Simultaneously, in cancer genetics and cardiovascular genetics, more accurate risk prediction is coupled with greater uncertainty. The healththreatening nature of the information and risks to close relatives generate fears, worries, and concerns that may inhibit adherence to medical recommendations and affect family relationships. As such, a psychotherapeutic approach to genetic counseling is often engaged in these
Genetic Counseling and Central Tenets of Practice

settings (see Ingles 2019; Platt 2019; Schienda and Stopfer 2019). Similarly, in the neurogenetics and neurodevelopmental subspecialties, the psychological impact of the conditions on individuals and families has long been recognized as profound (see Blesson and Cohen 2019; Goldman 2019). As such, the therapeutic relationship remains at the center of genetic counseling, even as the profession recognizes that less engagement with a patient/client may be appropriate in situations in which the information is less alarming or readily addressed.

\section{GENETIC COUNSELING PRACTICE MODELS}

To compare and contrast service delivery options, the roots of psychotherapeutic counseling are important considerations. Historically, Dr. Seymour Kessler described genetic counseling as composed of two practice models: a teaching model and a counseling model (Kessler 1997). These models have distinct goals that can be at cross purposes and must be integrated to achieve the goals of practice. The teaching model involves effective communication of information relevant to the patient/client. In this model, the counselor has more authority in the relationship and is looked to as an expert by the patient/client -as the one who knows the information sought. In processing the information, the patient/client experiences psychological responses. In the counseling model, the patient/client is the authority on her/his thoughts, feelings, and behaviors. The counselor guides her/him toward opportunities to gain personal insight, identify resources, and cope effectively with any health threat that presents. Integrating these two models to address a patient/client's needs is challenging but comprises a key professional skill in genetic counseling. Use of one model without the other is insufficient to successfully meet the patient/client's needs as defined in traditional client-centered care.

The integration of teaching and counseling practice models in genetic counseling practice is often referred to as psychoeducational (Biesecker et al. 2019). More recently the practice has been described as psychotherapeutic based on the similarity of genetic counseling to the 
definition of psychotherapy (Austin et al. 2014; Biesecker et al. 2017, 2019). Yet antithetical to these descriptors, evidence from some studies demonstrates that rather than integrating teaching and counseling models in practice, genetic counseling tends to favor the teaching model at the cost of the counseling model (Ellington et al. 2005; Meiser et al. 2008; Joseph and Guerra 2015; Joseph et al. 2017, 2019). Here, I describe genetic counseling as psychotherapeutic to highlight the importance of the counseling model and the significant limitations of genetic counseling when it is conceptualized and delivered as an encounter centered primarily on genetic information provision. This unilateral approach fails to attend to patients/clients' psychological responses and needs that are not remarkable in all cases, but are in many (Kessler 1997; Biesecker et al. 2017).

Despite the importance of therapeutic engagement with patients/clients, genetic counseling is more often dominated by "counselorspeak," which aims to communicate genetics concepts. As of August 2019, there is no published evidence explaining the prevalence of this phenomenon. Many opinion pieces have floated ideas about why counselors practice as such, including the rapid development of genomic science that focuses their attention on the science; their affinity for explaining how genetics "works" to their patients/clients; the complexity of addressing psychological responses that may feel at times intimidating; and the sense that they may feel less well-prepared by their graduate education to provide an integrated practice model. This pattern remains a significant concern and growing challenge for the field as patients/clients are demonstrably better served through empathic engagement. It is a particularly crucial point of consideration for the profession as alternative service delivery models are being introduced to replace components of genetic counseling.

Given the nature of genetic information and its close connection to health and wellness, the burden of disease, and the implications for relatives and future reproductive decisions, the likelihood for patients/clients to concern themselves with related thoughts, feelings, worries, and behaviors is high. Patients/clients should be offered sufficient opportunity to process information, deliberate on options, express their values and beliefs, and make informed decisions. Thus, actualizing a more balanced practice model that integrates both teaching and counseling is important in meeting the needs of many patients/clients.

\section{STATE OF THE PROFESSION}

Since Kessler introduced the two models of practice, the profession of genetic counseling has expanded rapidly, with recent growth fueled by findings from a 2016 workforce report commissioned by the National Society of Genetic Counselors (NSGC) that concluded there were an inadequate number of genetic counselors to meet growing service demands and patient/ client needs (https://www.nsgc.org/page/gene tic-counselor-workforce-initiatives-532, accessed July 1, 2019). In response to the identified need for additional genetic counselors, existing programs have expanded to take more students; 14 new programs have opened (bringing the total in North America to 49 as of July 2019) and at least three more are under development (https ://www.gceducation.org/program-directory/, accessed July 1, 2019). The existing U.S. programs graduate about 200 genetic counselors annually, and the January 2019 membership of NSGC totaled nearly 5000 members. Genetic counselors work in increasingly diverse positions beyond the clinical setting, including, for example, as founders and CEOs of telegenetic counseling companies, research scientists, laboratory managers, and academic professors. This expansion has facilitated growth in our capacity to help patients/clients within expanded delivery models, contribute evidence to guide practice, and proffer expert interpretation of genomic data. Throughout this collection, the primary focus is on the practice of genetic counseling in direct patient care, although expanded roles are delineated. Although much of genetic counseling practice is not yet informed by an evidence base, increasingly there are emerging data by which to assess the effectiveness of genetic counseling. 


\section{ROLE OF GENETIC TESTING}

Although genetic counseling in direct patient care and genetic testing have been intertwined since the start of the profession, the onslaught of technical discoveries has led to an era in which testing plays a far more prominent role. There are increasing ways for people to undergo testing without genetic counseling, via direct to consumer testing (e.g., 23\&Me) and patient-initiated testing (https://www.invitae.com/en/patienttesting/). Although expanded testing options have greatly enhanced the likelihood that patients/clients learn more definitive information about their risk status, testing is not always an option, nor is it always a solution to the challenges that face patients/clients. Further, although genetic/genomic testing expands the resources available to genetic counseling patients/ clients, increasing testing uptake is not and should not be the goal of genetic counseling.

Helping counselees to determine whether testing may be useful, or which test is indicated, often does fall to the expertise of the genetic counselor. Yet in genetic counseling, the goal is to promote informed decision-making. In prenatal testing, genetic counseling facilitates patients/clients' consideration of their personal values and beliefs and fosters deliberation of the relative benefits of undergoing testing to make a preference-based decision. In the end, genetic counseling in most settings comes down to helping patients/clients to understand what genetic vulnerability and/or risk means to them-how these issues are interpreted and valued, and how they may be managed for personal or family benefit. A stark exception is in recommending medically indicated testing that can mitigate health risk and reduce morbidity and mortality. Common examples are cancer screening recommendations for those at high heritable risk, and cardiac screening for those with an inherited cardiovascular condition (see Forman and Sotelo 2019; Platt 2019). As such, the outcomes of genetic counseling include its clinical utility in addition to personal utility in whether it helped to better understand health risks and how to cope with them when there is no follow-up screening or intervention to recommend (Koh- ler et al. 2017a,b), in addition to psychological well-being (Athens et al. 2018).

\section{SCALING OF GENETIC COUNSELING}

As the demand for genetic counseling services has rapidly outpaced its availability (https:// www.nsgc.org/page/genetic-counselor-work force-initiatives-532, accessed July 1, 2019), a priority for the profession is the scalability of resources. To deal with the limited availability of services, triage of patient/client needs is a logical first step. Matching the service model to patient/client needs will be essential to effective outcomes. Yet evidence to guide triage is limited and there are constraints, primarily the challenges for patients/clients to identify the most appropriate providers within a fractionated health-care system with limited third-party coverage for genetic counseling services.

Patient/client-centered triage would prioritize genetic counseling for those with the greatest psychological need. Examples include those living with high levels of risk; handling personal experiences with illness, loss, and disability; dealing with complex inheritance of life-threatening conditions; and struggling to learn how to cope effectively with genetic risk information. Yet these notions of who may benefit most from clinical services are not evidence-based; this is research that needs to be done to ensure that those with the greatest need meet with a genetic counselor (Biesecker 2018).

\section{Alternative Service Delivery Modes}

Scaling access to genetic counseling involves increasing the number of genetic counselors, but also the introduction of alternative service delivery models. These will need to be embraced following assessment of how effective and how well-accepted they are as methods of delivering lower-risk genetic information. The shift in service delivery to include the use of interactive digital platforms to provide genetic information is already underway. Although research into alternative delivery models is ongoing via randomized controlled trials (Athens et al. 2018), evidence to inform targeted use of a variety of 
service delivery models across settings is limited. For now, existing evidence can be used to guide triage, but the array of service delivery models will need to be assessed for their effectiveness in meeting patient/client needs. Subspecialties are working to address the demand for services and their early efforts in the use of new technology to provide information and address the needs of their patients/clients.

Prior to 2018, 54 randomized controlled trials (RCTs) of genetic counseling over 25 years were published, according to a systematic literature review by Athens et al. (2018). More have been published since. Of the trials in the review, 31 compared an alternative service delivery model, such as telegenetic counseling, to usual care (in-person genetic counseling). The services provided via telegenetic counseling followed the same client-centered protocol as those provided in person. In each trial, the alternative delivery model was as effective, or noninferior, to usual care. One such RCT in the cancer genetics setting also demonstrated significant cost savings with telegenetic counseling (Buchanan et al. 2015). As $76 \%$ of these trials were conducted in the cancer genetics setting, use of telegenetic counseling services in this setting can accurately be discussed as an evidence-based practice equal in value to in-person counseling.

Other service delivery models aim to streamline components of genetic counseling practice. Digital platforms have been developed to communicate genetic information and its health implications without the involvement of a genetic counselor. A recent study comparing information delivery systems, including an online version that can be kept current, suggests alternative ways exist to meet some patients/clients' needs for certain types of information, particularly information that is less likely to lead to significant psychological responses (Persky et al. 2019).

Digital platforms have been studied over the past 20 years as an alternative way to return certain genetic risk information. In 2001, a randomized trial comparing the return of test results to low-moderate risk participants did so effectively without incurring psychological distress and to the patient/client's satisfaction
(Green et al. 2001). This finding supports substituting genetic counseling with well-designed educational resources with the residual option of following up with a genetic counselor with questions or concerns. Yet few studies have subsequently addressed the same question, and more evidence is needed to discern when this would be sufficient in meeting patient/client needs. More recently, platforms programmed to return less threatening risk information from genome sequencing, such as carrier status among postreproductive adults, have been found to be noninferior to in-person return (Biesecker et al. 2018; Lewis et al. 2018), further suggesting that there may not be a need for genetic counselors to return all types of genetic risk information. Although results from these trials are beginning to assess differences in patient/client needs, it remains difficult to parse patients/clients according to who is more likely to have significant psychological responses to their risk and health management needs and to ensure that they are not overlooked by an inadequate mode of service delivery.

Many of the attributes of digital platforms, such as dual-channel messaging-coupling audio to video-and use of quizzes to check for understanding, can enhance learning for patients/clients who benefit from taking in new information through multiple means (Kraft et al. 2017). Digital platforms can also extend access of services to patients/clients who may otherwise not be able to travel to a medical center. As such, they represent a potentially valuable resource for meeting the needs of the expanding number of people whose lives will be touched by genomics. For example, in a minority of prenatal settings, genetic counselors provide in-person pretest genetic counseling for noninvasive prenatal screening (NIPS) (see Stoll and Jackson 2019). Yet much of prenatal screening is being done by obstetricians who have less training in genetics and little time to explain the potential outcomes of screening. Because its preference-based nature is important to uphold, one could argue that a well-designed digital platform that includes a decision-making intervention to review personal values and beliefs could be widely used. If careful study proves it to be 
accessible, acceptable, and effective in teaching pregnant women and their partners about their screening options, it would help to address the workforce shortages. Genetic counselors could then focus their services on those patients who are struggling with decisions about screening and those who receive abnormal findings that require intensive discussion and deliberation to facilitate an informed decision on follow-up testing and pregnancy options.

Accordingly, Kuppermann et al. (2009, 2014) assessed a prenatal testing educational platform using an RCT design that compared outcomes to in-person genetic counseling. In the 2014 trial, both groups successfully learned key information about prenatal testing. Yet, fewer people who were randomized to the platform chose to undergo invasive prenatal testing, raising questions about whether this outcome reflected enhanced preference-based decisionmaking or potential internal biases in the program.

A more comprehensive service is offered by Counsyl via an interactive digital platform, Counsyl Complete. It uses video to teach pregnant women about NIPS and includes a portal for return of results (Arjunan et al. 2019). The woman's obstetrics provider must authorize her to use the site, and women have the option to request and meet with a genetic counselor. Those with inconclusive results are not able to receive their results via the platform and are directed to meet with a counselor. Over 39 months, 67,122 women received results via the platform. Of those requesting genetic counseling (4673), more were likely to have received a positive screen result, to be of advanced maternal age, to have a family history of concern, to have had a past pregnancy with a chromosomal finding, or to represent a high-risk pregnancy. Patient satisfaction was uniformly high among those with both negative and positive findings, with very few exceptions. Yet, there was no assessment of whether participants made an informed choice to undergo screening or whether they sufficiently understood the implications of their results. Further, when commercial entities develop educational platforms, they need to be scrutinized for bias in how the information is
Genetic Counseling and Central Tenets of Practice

presented, given that their ultimate objective is to sell tests. This is not to say that Counsyl, or any other testing company, aims to persuade women to undergo screening they prefer not to pursue, but caution is warranted in cases in which there is clear conflict of interest. Additional evidence is needed to assess the value of such platforms to women making a value-based personal decision such as whether to undergo NIPS.

\section{Augmenting Genetic Counseling}

Beyond those services aiming to replace genetic counseling or practice components, there are other promising resources to augment service provision, such as chatbots. Clear Genetics developed the AI chatbot GIA (Genetic Information Assistant) and programmed "her" to answer common questions asked by genetic counseling patients/clients as they are selecting services. In certain circumstances, this may even be preferable. For example, potential patients/ clients may prefer to ask about insurance coverage for genetic services in advance of prenatal screening, which is a discussion that can take time and often distract from the true intention of the counseling session. In a pilot study conducted with research participants enrolled in MyCode, a large exome sequencing cohort study at Geisinger Laboratories, participants who received results indicating the presence of a pathogenic variant in a hereditary cancer gene found GIA to be accessible, engaging, and informative (Nazareth et al. 2019). This iteration of GIA reminds patients/clients to tell close relatives about their own genetic test results and communicate their implications for their relatives' risks while also encouraging them to undergo testing. These important follow-up issues are typically addressed by genetic counselors, who often do not have time to remind patients. In this capacity, GIA can save counselors time and effort, especially with respect to delivery of repetitive information. Use of GIA or other AI resources can also result in patients/clients bringing more complex and nuanced questions to genetic counselors for answers, arguably a better use of the professionals' time. There are many other 


\section{B. Biesecker}

ways that genetic counseling adjuncts will serve to help streamline genetic counseling services, preserving in-person counseling for the most challenging cases.

The expanding ways that genomics is intersecting the lives of patients/clients suggest that all who seek understanding of their genetic risk status and health management needs may not require psychotherapeutic genetic counseling. Yet scaling of services should occur without losing the gold standard of psychotherapeutic care for those patients/clients who face the greatest health threats or complex decisions.

\section{EVIDENCE TO GUIDE PRACTICE}

These alternative and augmented service delivery models for use in the wake of expanding roles and responsibilities in genetic counseling need to be properly assessed to determine their relative success in meeting a wide variety of patient/client needs. Developing and evaluating creative solutions to meet systemic health delivery needs, such as educating other medical providers about genomics, are needed. Providers are currently ill-prepared to address their patients' queries about direct-to-consumer genetic test results, among other genetics/genomics-related questions. This could be an opportunity for genetic counselors to take the lead in developing and evaluating strategies for educating practicing physicians and nurses about ways to help interpret and use genomic information, and in particular how to help patients/clients accept the uncertainties due to the limited evidence to interpret many findings.

Individuals who have pursued the still-new profession of genetic counseling are intellectually curious, thrive on change, and have demonstrated their ability to embrace the unique nature of each new professional challenge. Because of the small size and limited number of training programs, the application process has traditionally been competitive, and high academic standards have been maintained and strengthened (Stern 2012). With each new wave of genomic discoveries, genetic counselors have risen to lead in devising creative solutions for providing care. As genomics translates into mainstream medical care over the coming years, there will be even more challenges. Yet already, genetic counselors are looking ahead, playing a key role in the development of telegenetic counseling companies for alternative service delivery and chatbots pioneered as an adjunct to practice. An important component of the profession's approach to problem solving is a commitment to patient care, and innovation is accompanied by the simultaneous collection of evidence to identify the best means of addressing patients/clients' needs going forward.

As genetic counseling advances, it will be important to the profession to uphold its central tenets in the provision of client-centered care, or to revise them based on new evidence. It is of critical importance to accrue data about how the tenets are actualized and how they relate to positive patient/client outcomes. Evidence can be used to ensure that patient/client needs are met, regardless of service delivery mode. It can also be used to preserve the limited work force of counselors for casework that demands cutting-edge complex information delivery coupled with advanced counseling skills. Evidence-based triage will be vital to keeping pace with demand and successfully addressing specific patient/client needs.

\section{REFERENCES}

${ }^{*}$ Reference is also in this subject collection.

Arjunan A, Ben-Shachar R, Kostialik J, Johansen Taber K, Lazarin GA, Denne E, Muzzey D, Haverty C. 2019. Technology-driven noninvasive prenatal screening results disclosure and management. Telemed J E Health. doi:10 .1089/tmj.2018.0253

Athens BA, Caldwell SL, Umstead KL, Connors PD, Brenna E, Biesecker BB. 2018. A systematic review of randomized controlled trials to assess outcomes of genetic counseling. J Genet Couns 26: 902-933. doi:10.1007/s10897-0170082-y

Austin J, Semaka A, Hadjipavlou G. 2014. Conceptualizing genetic counseling as psychotherapy in the era of genomic medicine. J Genet Couns 23: 903-909. doi:10.1007/ s10897-014-9728-1

Biesecker BB. 2018. Genetic counselors as social and behavioral scientists in the era of precision medicine. Am J Med Genet C 178: 10-14. doi:10.1002/ajmg.c.31609

Biesecker BB, Peters K. 2001. Process studies in genetic counseling: peering into the black box. Am J Med Genetics 106: 191-198. doi:10.1002/ajmg.10004 
Biesecker BB, Austin J, Caleshu C. 2017. Theories for psychotherapeutic genetic counseling: fuzzy trace theory and cognitive behavior theory. J Genet Couns 26: 322-330. doi:10.1007/s10897-016-0023-1

Biesecker BB, Lewis KL, Umstead KL, Johnston JJ, Turbitt E Fishler KP, Patton JH, Miller IM, Heidlebaugh AR, Biesecker LG. 2018. Web platform vs. in-person genetic counselor for return of carrier results from exome sequencing: a randomized clinical trial. JAMA Internal Med 178: 338-346. doi:10.1001/jamainternmed.2017 .8049

Biesecker BB, Peters K, Resta R. 2019. Advanced genetic counseling theory and practice. Oxford University Press, Cambridge.

* Blesson A, Cohen JS. 2019. Genetic counseling in neurodevelopmental disorders. Cold Spring Harb Perspect Med. doi:10.1101/cshperspect.a036533

Buchanan AH, Datta SK, Skinner CS, Hollowell GP, Beresford HF, Freeland T, Rogers B, Boling J, Marcom PK, Adams MB. 2015. Randomized trial of telegenetics vs. in-person cancer genetic counseling: cost, patient satisfaction and attendance. J Genet Counsel 24: 961-970. doi:10.1007/s10897-015-9836-6

* Cho MT, Guy C. 2019. Evolving roles of genetic counselor in the clinical laboratory. Cold Spring Harb Perspect Med. doi:10.1101/cshperspect.a036574

Ellington L, Roter D, Dudley WN, Baty BJ, Upchurch R, Larson S, Wylie JE, Smith KR, Botkin JR. 2005. Communication analysis of BRCA1 genetic counseling. J Genet Couns 14: 377-386.

* Forman A, Sotelo J. 2019. Tumor-based genetic testing and familial cancer risk. Cold Spring Harb Perspect Med. doi:10.1101/cshperspect.a036590

* Goldman JS. 2019. Predictive genetic counseling and testing for neurodegenerative diseases: past, present, and future. Cold Spring Harb Perspect Med. doi:10.1101/cshperspect .a036525

Green MJ, Biesecker BB, Mclnerney AM, Mauger D, Fost N. 2001. An interactive computer program can effectively educate patients about genetic testing for breast cancer susceptibility. Am J Med Genet 103: 16-23.

* Ingles J. 2019. Psychological issues in managing families with inherited cardiovascular diseases. Cold Spring Harb Perspect Med. doi:10.1101/cshperspect.a036558

Joseph G, Guerra C. 2015. To worry or not to worry: breast cancer genetic counseling communication with low-income Latina immigrants. J Community Genet 6: 63-76. doi:10.1007/s12687-014-0202-4

Joseph G, Pasick RJ, Schillinger D, Luce J, Guerra C, Cheng JKY. 2017. Information mismatch: cancer risk counseling with diverse underserved patients. J Genet Couns 26: 1090-1104. doi:10.1007/s10897-017-0089-4

Joseph G, Lee R, Pasick RJ, Guerra C, Schillinger D, Rubin S. 2019. Effective communication in the era of precision medicine: a pilot intervention with low health literacy patients to improve genetic counseling communication. Eur J Med Genet 62: 357-367. doi:10.1016/j.ejmg.2018.12 .004

Kessler S. 1997. Psychological aspects of genetic counseling. IX. Teaching and counseling. J Genet Couns 6: 287-295. doi:10.1023/A:1025676205440
Genetic Counseling and Central Tenets of Practice

Kohler JN, Turbitt E, Biesecker BB. 2017a. Personal utility in genomic testing: a systematic literature review. Eur J Human Genet 25: 662-668. doi:10.1038/ejhg.2017.10

Kohler J, Turbitt E, Lewis K, Wilfond B, Jamal L, Peay H, Biesecker L, Biesecker B. 2017b. Defining personal utility in genomics: a Delphi study. Clin Genet 92: 290-297. doi:10.1111/cge.12998

Kraft SA, Constantine M, Magnus D, Porter KM, Lee SS, Green M, Kass NE, Wilfond BS, Cho MK. 2017. A randomized study of multimedia informational aids for research on medical practices: implications for informed consent. Clin Trials 14: 94-102.

Kuppermann M, Norton ME, Gates E, Gregorich SE, Learman LA, Nakagawa S, Feldstein VA, Lewis J, Washington AE, Nease RF Jr. 2009. Computerized prenatal genetic testing decision-assisting tool: a randomized controlled trial. Obstet Gynecol 113: 53-63.

Kuppermann M, Pena S, Bishop JT, Nakagawa S, Gregorich SE, Sit A, Vargas J, Caughey AB, Sykes S, Pierce L, et al. 2014. Effect of enhanced information, values clarification, and removal of financial barriers on use of prenatal genetic testing: a randomized clinical trial. J Am Med Assoc 312: 1210-1217.

Lewis L, Umstead KL, Johnston JJ, Miller IM, Thompson LJ, Fishler KP, Biesecker LG, Biesecker BB. 2018. Outcomes of counseling after education about carrier results: a randomized controlled trial. Am J Hum Genet 102: 540-546. doi:10.1016/j.ajhg.2018.02.009

Matias M, Wusik K, Neilson D, Zhang X, Alexander-Valencia C, Collins K. 2019. Comparison of medical management and genetic counseling options pre- and post-whole exome sequencing for patients with positive and negative results. J Genet Couns 28: 182-193.

Meiser B, Irle J, Lobb E, Barlow-Stewart K. 2008. Assessment of the content and process of genetic counseling: a critical review of empirical studies. J Genet Couns 17: 434-451. doi:10.1007/s10897-008-9173-0

Milliron BJ, Bruneau M, Obeid E, Gross L, Bealin L, Smaltz C, Giri VN. 2019. Diet assessment among men undergoing genetic counseling and genetic testing for inherited prostate cancer: exploring a teachable moment to support diet intervention. Prostate 79: 778-783. doi:10.1002/pros .23783

Montgomery SV, Barsevick AM, Egleston BL, Bingler R, Ruth K, Miller SM, Malick J, Cescon TP, Daly MB. 2013. Preparing individuals to communicate genetic test results to their relatives: report of a randomized control trial. Fam Cancer 12: 537-546. doi:10.1007/s10689-0139609-z

National Society of Genetic Counselors' Definition Task Force, Resta R, Biesecker BB, Bennett RL, Blum S, Hahn SE, Strecker MN, Williams JL. 2006. A new definition of genetic counseling: National Society of Genetic Counselors' Task Force report. J Genet Couns 15: 77-83.

Nazareth S, Simmons E, Snir M, Shohat M, Goldberg J. 2019. Use of a chatbot to offer pre-test education for expanded carrier screening. Abstract 8836 American College of Medical Genetics Annual Conference, Seattle, WA

Persky S, Kistler WD, Klein WMP, Ferrer RA. 2019. Internet versus virtual reality settings for genomics information 
B. Biesecker

provision. Cyberpsychol Behav Soc Netw 22: 7-14. doi:10 $.1089 /$ cyber.2017.0453

* Platt J. 2019. A person-centered approach to cardiovascular genetic testing. Cold Spring Harb Perspect Med. doi:10 $.1101 /$ cshperspect.a036624

* Ramos E. 2019. Genetic counselors, personalized medicine, and precision health. Cold Spring Harb Perspect Med. doi:10.1101/cshperspect.a036699

Resta R, Biesecker B, Bennett R, Blum S, Estabrooks Hahn S, Strecker M, Williams JL. 2018. How is the NSGC definition of genetic counseling being used? Abstract C-330 presented at The National Society of Genetic Counselors Annual Education Conference, Atlanta, GA

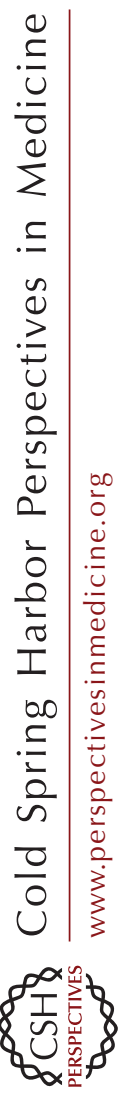

Rutherford S, Zhang X, Atzinger C, Rushman J, Meyers M. 2014. Medical management adherence as an outcome of genetic counseling in a pediatric setting. Genet Med 16: 157-163.

* Schienda J, Stopfer J. 2019. Cancer genetic counseling-current practice and future challenges. Cold Spring Harb Perspect Med. doi:10.1101/cshperspect.a036541
Stern A. 2012. Telling genes: the story of genetic counseling in America. Johns Hopkins University Press, Baltimore, $\mathrm{MD}$.

* Stoll K, Jackson J. 2019. Supporting patient autonomy and informed decision making in prenatal genetic testing. Cold Spring Harb Perspect Med. doi:10.1101/cshperspect .a036509

Subas T, Luiten R, Hanson-Kahn A, Wheeler M, Caleshu C. 2019. Evolving decisions: perspectives of active and athletic individuals with inherited heart disease who exercise against recommendations. J Genet Couns 28: 119-129. doi:10.1007/s10897-018-0297-6

Veach PM, Bartels DM, LeRoy B. 2007. Coming full circle: a reciprocal-engagement model of genetic counseling practice. J Genet Couns 16: 713-728.

Zakas AL, Leifeste C, Dudley B, Karloski E, Afonso S, Grubs RE, Shaffer JR, Durst AL, Parkinson MD, Brand R. 2019. The impact of genetic counseling on patient engagement in a specialty cancer clinic. J Genet Couns. doi:10.1002/ jgc4.1149 


\title{
$\& \mathrm{CSH} \&$ Cold Spring Harbor

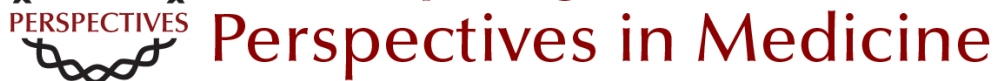

\section{Genetic Counseling and the Central Tenets of Practice}

\author{
Barbara Biesecker
}

Cold Spring Harb Perspect Med 2020; doi: 10.1101/cshperspect.a038968 originally published online September 30, 2019

\section{Subject Collection Genetic Counseling: Clinical Practice and Ethical Considerations}

Genetic Risk Assessment in Psychiatry Holly Landrum Peay

Birds of a Feather? Genetic Counseling, Genetic Testing, and Humanism Robert Resta

Bridging the Gap between Scientific Advancement and Real-World Application: Pediatric Genetic Counseling for Common Syndromes and Single-Gene Disorders Julie A. McGlynn and Elinor Langfelder-Schwind

Genetic Counseling, Personalized Medicine, and Precision Health Erica Ramos

Tumor-Based Genetic Testing and Familial Cancer Risk Andrea Forman and Jilliane Sotelo

A Person-Centered Approach to Cardiovascular Genetic Testing Julia Platt

Evidence-Based Genetic Counseling for Psychiatric Disorders: A Road Map Jehannine C. Austin

Supporting Patient Autonomy and Informed Decision-Making in Prenatal Genetic Testing Katie Stoll and Judith Jackson
Impact of Emerging Technologies in Prenatal

Genetic Counseling

Blair Stevens

Genetic Counseling and Assisted Reproductive

Technologies Debra Lilienthal and Michelle Cahr

Evolving Roles of Genetic Counselors in the Clinical Laboratory Megan T. Cho and Carrie Guy

Psychological Issues in Managing Families with Inherited Cardiovascular Diseases Jodie Ingles

Informed Consent in the Genomics Era Shannon Rego, Megan E. Grove, Mildred K. Cho, et al.

Predictive Genetic Counseling for

Neurodegenerative Diseases: Past, Present, and Future Jill S. Goldman

Cancer Genetic Counseling--Current Practice and Future Challenges Jaclyn Schienda and Jill Stopfer

Regulating Preimplantation Genetic Testing across the World: A Comparison of International Policy and Ethical Perspectives Margaret E.C. Ginoza and Rosario Isasi

For additional articles in this collection, see http://perspectivesinmedicine.cshlp.org/cgi/collection/ 